\title{
On the behavior of lightning return stroke current incidence to tall towers
}

\begin{abstract}
The return stroke current in the case of a lightning strike on a tall structure is affected by different tower and channel parameters such as the velocity of the return stroke current, the height of the observation point along the structure, the lightning channel and the reflection coefficients at the top and bottom of the structure. This paper will consider all these factors in the behaviour of the return stroke. The current wave shapes at different heights along tower and channel were modeled and the simulated current at tower top was compared to the corresponding measured current. Moreover, the effects of reflection factors and other important parameters on the values of current peak were considered and the results were discussed accordingly.
\end{abstract}

Keyword: Lightning; Tall structures; Return stroke current 